\title{
Dietary phytochemicals as a promising nutritional strategy for sarcopenia: a systematic review and meta-analysis of randomized controlled trials
}

\author{
Hye Yun Jeong ${ }^{1}$ and Oran Kwon ${ }^{1,2^{*}}$ (D)
}

\begin{abstract}
The decline in skeletal muscle mass and strength, also called sarcopenia, accelerates with age, leading to negative health outcomes and poor quality of life. Diet is important to promote health and plays a key role in muscle aging. Plant-based foods have recently received attention as sources of phytochemical components to attenuate loss of muscle mass and strength in older adults. This systematic review and meta-analysis evaluated the benefits of botanical extracts and their phytochemical compounds for muscle health in older adults. Randomized controlled trials were identified via systematic searches of four electronic databases (PubMed, Cochrane Library, Web of Science, and KoreaMed) up to June 2021 and were quality assessed. The results of muscle strength, mass, and physical performance were pooled using a random-effects model. Fourteen studies involving 528 subjects aged between 50 and 80 years met the inclusion criteria. Dietary phytochemicals significantly increased handgrip strength $[0.90 \mathrm{~kg} ; 95 \%$ confidence interval (Cl) $0.26-1.53, p=0.01]$ and physical performance (timed up-and-go test: $-0.5 \mathrm{~s}, 2.73$ times; $95 \% \mathrm{Cl}-0.84$ to $-0.15, p<0.01 ; 30$-s chair stand test: $95 \% \mathrm{Cl} 0.88-4.59, p<0.01$; 6-min walk test: $29.36 \mathrm{~m} ; 95 \% \mathrm{Cl} 14.58-44.13, p<$ 0.0001 ) but had no effect on improvement in muscle mass. Publication bias evaluated by funnel plots and Egger's regression test demonstrated no evidence of substantial publication bias $(p>0.05)$. The findings of this systematic review and meta-analysis suggest that phytochemicals are a potential nutritional strategy to improve muscle health in older adults.
\end{abstract}

Keywords: Meta-analysis, Phytochemical, Randomized controlled trial, Sarcopenia

\section{Introduction}

With the rapid increase in life expectancy and the number of older adults over the last century, the number of older people with age-related diseases and disabilities has also increased [1]. The loss of skeletal muscle mass (MM) and function, termed sarcopenia, is a major cause of the muscle dysfunction and physical inactivity observed with aging [2]. The prevalence of sarcopenia is approximately

\footnotetext{
*Correspondence: orank@ewha.ac.kr

1 Department of Nutritional Science and Food Management, Ewha

Womans University, Seoul 03760, Republic of Korea

Full list of author information is available at the end of the article
}

$25 \%$ after the age of 60 and increases to almost $50 \%$ in people aged $>80$ years [3-5]. The decline in skeletal MM and muscle strength (MS) cause adverse health outcomes in older adults, accelerating the risk of muscle dysfunction, poor quality of life, hospitalization, and even death [6-10].

Despite recent advances in research on age-related diseases [6,7], challenges remain in diagnosing and treating sarcopenia in clinical practice and preventing age-related decline in muscle health. Exercise is generally considered the most effective intervention [11]. However, additional treatment strategies are needed because many older adults do not meet the physical activity recommendations 
[12]. In this context, several studies have documented the importance of dietary supplementation with protein and vitamin D as a countermeasure for sarcopenia [13-18]. According to Cummings et al. [13] oral supplementation with protein and vitamin D improves skeletal MM and MS and physical performance, regardless of the level of physical activity in older sarcopenic patients.

Oxidative damage due to the accumulation of free radicals contributes to aging and age-related phenotypes, including sarcopenia. Accordingly, several recent in vitro and in vivo have drawn attention to dietary phytochemicals, either alone [19-21] or in combination [20,22], as non-pharmacological strategies for older adults with low levels of muscle health or sarcopenia. These phytochemicals are predominantly found in fruits, vegetables, whole grains, nuts, and herbs and may simultaneously act on multiple cellular targets with anti-inflammatory and antioxidant activity [23]. The synergistic combination of various phytochemical extracts in plant-based foods can provide a wide range of health benefits beyond the basic nutritional value of a food product [24]. An up-to-date assessment of the literature on the benefits of botanical bioactive components for improving muscle health in the older population might promote further research and clinical studies to support and validate the findings. Therefore, this systematic review analyzes the current trends in clinical research of dietary phytochemicals for sarcopenia and evaluates the effects of supplementation on MM and muscle function in the older population.

\section{Methods}

The internationally accepted preferred reporting items for systematic reviews and meta-analyses (PRISMA) guidelines [25] have been followed for all steps in this research.

\section{Literature search}

Four electronic databases (PubMed, Cochrane Library, Web of Science, and KoreaMed) were searched to identify clinical trials that investigated the effects of dietary phytochemicals on muscle health in older adults.
Keywords were searched by combining $\mathrm{MeSH}$ with text terms related to phytochemicals and sarcopenia. We also examined previously published systematic reviews and references cited in the retrieved articles to identify potentially eligible studies. The search results were exported to a Microsoft Excel sheet, and duplicate articles were removed. The search strategy and search terms used for this research are detailed in Table 1.

\section{Study selection}

The review included intervention studies published in English or Korean and a sample size of a least 10 subjects. All studies included a clarification of the exposure (i.e., type of botanical food, amount, dose, duration of intervention, and frequency of supplementation) and evaluated at least one muscle health outcome (skeletal muscle-related function, body composition, and physical performance). Intervention studies using phytochemicals or commercial products that did not specify botanical foods were excluded, along with conference abstracts, reviews, trial protocols, book chapters, studies with no placebo group, case reports, and opinions or commentaries. Studies were required to include healthy subjects aged $\geq 40$ years in both genders. Subjects from all races or ethnicities and all settings (e.g., local communities, nursing homes, hospitals) worldwide were considered. A detailed list of the inclusion and exclusion criteria is provided in Table 2.

\section{Data extraction}

The researchers reviewed all eligible studies, and each study was given an identifying code. Information on subjects (number of subjects, mean age, country), botanicals and phytochemicals (type, duration of intervention), exercise program (if applicable: type, frequency), and group (dose, placebo group) was extracted from relevant studies. Additionally, different muscle health indices (MM, MS, and performance) were extracted according to the guidelines suggested by the European Working Group on Sarcopenia in Older People (EWGSOP) [6]. MM, lean mass (LM), fat mass (FM), fat-free mass

Table 1 Search strategy

\begin{tabular}{ll}
\hline Search number & Search term/combinations \\
\hline$\# 1$ & [phytochemical (Tiab) or plant-based (Tiab) or extract (Tiab) or herb (Tiab)] \\
$\# 2$ & [sarcopenia (Tiab) or muscle weakness (Tiab) or muscle wasting (Tiab) or muscle atrophy (Tiab)] \\
$\# 3$ & {$[$ muscle mass (Tiab) or muscle strength (Tiab) or physical performance (Tiab) or walking speed } \\
& (Tiab) or skeletal muscle index (Tiab) or Timed Up-and-Go test (Tiab)] \\
$\# 4$ & [aged (Tiab) or age-related (Tiab) or older adults (Tiab) or elderly (Tiab)] \\
\hline
\end{tabular}


Table 2 Inclusion and exclusion criteria for study selection

\begin{tabular}{|c|c|c|}
\hline Parameter & Inclusion criteria & Exclusion criteria \\
\hline Article type & Full-text & \\
\hline Study design & $\mathrm{RCT}$ & $\begin{array}{l}\text { Conference abstracts; cross-sectional studies; longitudinal } \\
\text { studies; reviews; trial protocols; book chapters; studies with- } \\
\text { out placebo group; case reports; opinions; commentaries }\end{array}$ \\
\hline Language & English; Korean & \\
\hline Population & Healthy adults aged $\geq 40$ & \\
\hline Sample size & $\geq 10$ subjects & \\
\hline Exposure & $\begin{array}{l}\text { Supplementation; dietary phytochemicals available to older } \\
\text { adults clearly described; amount, dosage, frequency, and dura- } \\
\text { tion of intervention clearly described }\end{array}$ & \\
\hline Primary outcomes & $\begin{array}{l}\text { Measures of skeletal muscle-related function; body composition; } \\
\text { physical performance }\end{array}$ & \\
\hline
\end{tabular}

$R C T$ randomized controlled trial

(FFM), and skeletal muscle index (SMI) were used for MM assessment. Handgrip strength (HGS) and knee extension strength (KES) were recorded to assess MS changes. Results obtained from the timed up-and-go (TUG) test, 6-min walk test (6MWT), 30-s chair stand test (30-SCST), one-leg standing time (OLST), and 2-min step test (2MST) were recorded to evaluate muscle performance.

\section{Risk of bias and study quality assessment}

The risk of bias was assessed using the revised version of the Cochrane risk of bias tool (RoB 2.0), which consists of a fixed set of bias categories [26]. The researchers evaluated five specific categories as 'high risk of bias,' 'low risk of bias,' or 'some concerns' to establish the overall risk of bias: (i) bias arising from the randomization process; (ii) bias due to deviation from intended interventions; (iii) bias due to missing outcome data; (iv) bias in the measurement of the outcome, and (v) bias in the selection of reported results. The researchers could also present personal judgment about the risk of bias in each category, which is reflected in the overall judgment value.

\section{Statistical analysis}

All outcomes were meta-analyzed when at least two studies provided data. Outcomes, measured as the mean change from baseline to endpoint of the intervention study between the treatment and placebo groups, were considered continuous variables. The mean changes were calculated to determine the size effect of the outcomes. Effect sizes from each study were combined into a pooled effect size, weighted by the number of subjects. If the standard deviation of the difference was not available from the study, it was calculated by assuming a specific correlation coefficient.
Forest plots were represented to visually evaluate the changes in each variable and the corresponding 95\% confidence interval (CI) throughout the studies. Heterogeneity (between-study variation) was evaluated using the $I^{2}$ statistic [27]. It was considered low if $I^{2}<30 \%$, moderate if $I^{2}=30-75 \%$, and high if $I^{2}>75 \%$ [28]. The randomeffects model was used to account for the heterogeneity among studies. The significance level was set at $p<0.1$. The publication bias was examined using funnel plots and Egger's test [29]. No publication bias was considered when $p>0.05$. In addition, a sensitivity analysis was performed by excluding single studies one by one to examine their effect on the meta-analysis results.

Statistical analysis was performed using the meta-package of $\mathrm{R}$ software version 3.6.3 [30] with the standard methods recommended by the Cochrane Collaboration. The significance level was set at $p<0.05$.

\section{Results}

\section{Included studies}

The PRISMA flow diagram summarizes the study selection process (Fig. 1). The search yielded 305 articles. After removing duplicates $(\mathrm{n}=82)$ and screening the remaining articles $(n=225)$ by title and abstract, with three additional articles identified through manual searches, 197 were excluded as irrelevant. Twenty-eight full-text articles were screened for further assessment based on the inclusion and exclusion criteria. Of these, 15 that were eliminated were conference abstracts $(n=8)$, included unhealthy subjects (e.g., patients with cancer, arthritis, peripheral artery disease) $(n=3)$, included subjects aged $<40$ years $(n=2)$, and used non-botanical food $(\mathrm{n}=2)$. The remaining 13 studies were eligible for qualitative analysis and quantitative analysis [31-43]. One study included two separate trials of different age 


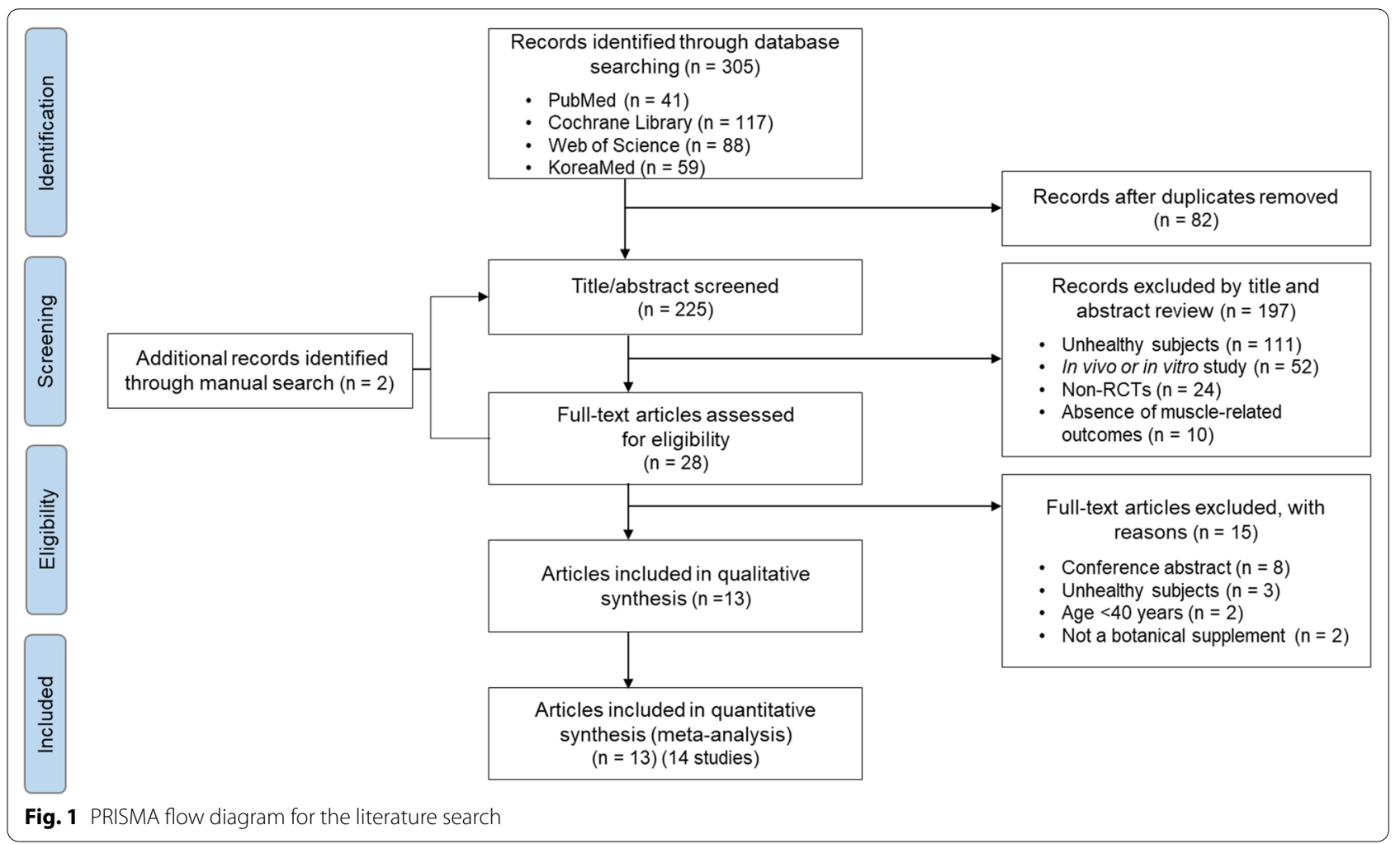

groups, and these trials were included as independent randomized control trials (RCTs) in this analysis [40].

The risk of bias was performed in all included studies (Fig. 2). Overall, there was a low risk of bias across all domains, particularly for bias in selecting reported results and bias arising from the randomization process. Two studies $[39,41]$ were observed to have a high risk for overall bias. One of these studies [41] did not analyze differences between groups at baseline and did not conduct appropriate statistical analysis without considering baseline characteristics and covariates. Additionally, the study by Schrager et al. [39], which used carrot juice as the placebo, was assessed as having a high risk of other bias due to the potential of the ingredients supplemented by the placebo group to affect the study outcomes. All studies reported all of the result data described in the methodology regarding the selection of reported results.

\section{Descriptive characteristics of studies}

A summary of the demographic data and study characteristics of the included RCTs is given in Table 3. The total number of subjects from the included studies was 528, with study sample sizes ranging from 12 to 73 subjects. The age ranged from $49.8 \pm 4.7$ to $80.2 \pm 5.6$ years. All studies were RCTs of parallel designs, except for one cross-over design study. Eleven studies included healthy older subjects (both men and women), and three studies included only female subjects (obese or postmenopausal women). In six studies [32, 34, 35, 38, 41, 43], some subjects were assigned to an exercise group (e.g., aqua exercise program, resistance training program, walking exercise program) during the intervention period, while the other eight conducted phytochemical interventions without exercise programs [31, 33, 36, 37, 39, 40, 42]. The locations of the nine studies conducted in Asia, were Korea $(\mathrm{n}=4)$, Japan $(\mathrm{n}=3)$, India $(\mathrm{n}=1)$, and Thailand $(\mathrm{n}=1)$ [31-36, 38, 41, 42], while two each were based in the USA $[39,40]$ and Canada $[37,43]$. The duration of intervention was 6 [39], 8 [36, 42], 12 [31, 33-35, $38,40,41], 16$ [32], and 24 weeks [37, 43]. As an indicator of muscle health, MM was measured in eight studies [32, 34, 35, 37, 40-43], MS was measured in twelve studies [31-36, 38-41, 43], and physical performance was assessed in ten studies [31, 32, 34-36, 38, 40, 41, 43].

\section{The effect of dietary phytochemicals on muscle health in older adults}

Meta-analysis was performed according to the EWGSOP guidelines [6], considering MM, MS, and performance as muscle health indicators in older adults. MM, LM, FM, and FFM were used for MM assessment. HGS and KES were used to assess MS changes. TUG, 6MWT, 30-SCST, OLST, and 2MST were recorded to assess muscle performance. 


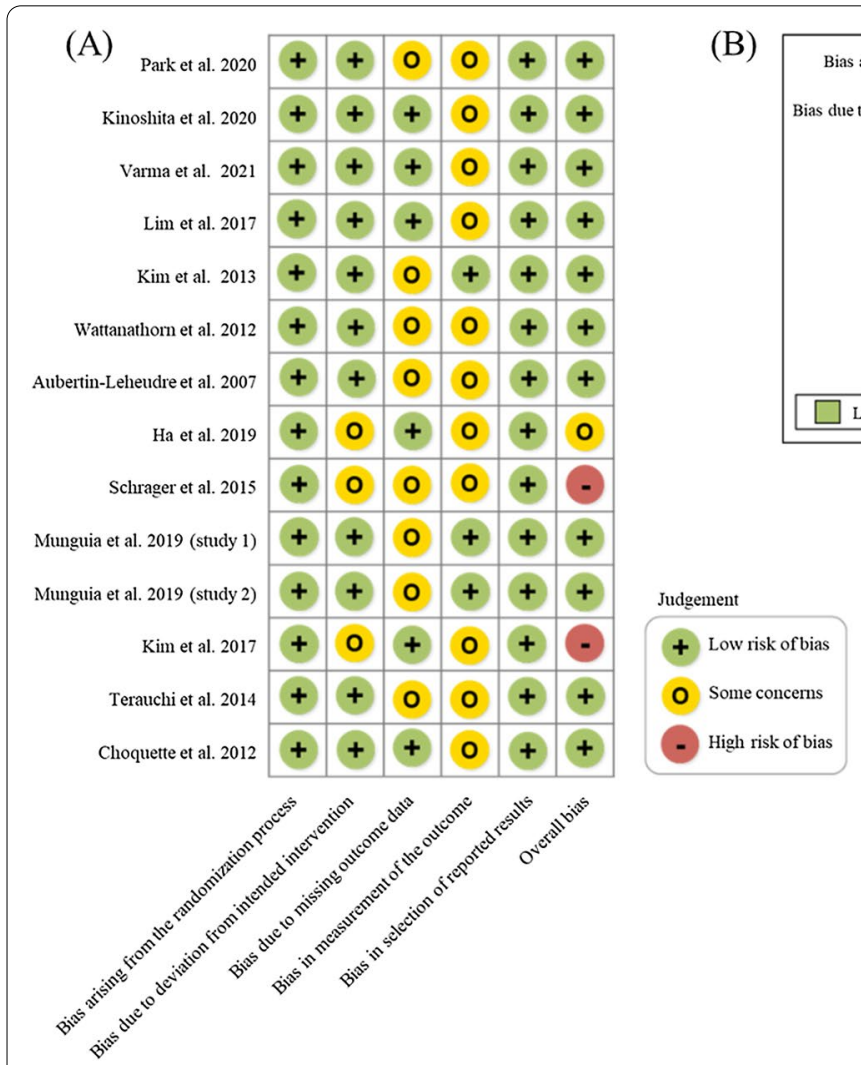

Fig. 2 Risk of bias assessment for randomized controlled trials. A Risk of bias summary and $\mathbf{B}$ risk of bias graph

\section{Muscle strength}

The effects of dietary phytochemicals on MS was assessed using HGS and KES (Fig. 3). The HGS results showed a moderate increase in subjects who supplemented with phytochemicals compared to those on placebo ( $\mathrm{n}=12 ; 0.90 \mathrm{~kg} ; 95 \%$ CI $0.26-1.53, p=0.01$ ), and there was low heterogeneity $\left(I^{2}=0 \% ; p=0.65\right)$ [31-36, 38-41, 43]. In contrast to the HGS data, there was no significant effect of phytochemicals on KES (n $=3 ;-0.07 \mathrm{Nm} ; 95 \% \mathrm{CI}-5.28$ to $5.13, p=0.98)$, and there was significant heterogeneity among studies $\left(I^{2}=\right.$ $71.7 \% ; p=0.03)[32,34,35]$.

\section{Muscle mass}

The effects of dietary phytochemicals on MM were evaluated using MM, FM, and LM (Fig. 4). Overall, dietary phytochemicals were ineffective for improving the MM ( $\mathrm{n}=5 ; 0.08 \mathrm{~kg} ; 95 \% \mathrm{CI}-0.64$ to $0.80, p=0.82$; $\left.I^{2}=0 \%\right)[32,34,35,41,42]$, FM ( $=4 ;-0.33 \mathrm{~kg} ; 95 \%$ CI -2.13 to $\left.1.47, p=0.72 ; I^{2}=0 \%\right)[34,37,41,42]$, and LM ( $\mathrm{n}=3$; $0.28 \mathrm{~kg} ; 95 \% \mathrm{CI}-0.56$ to $1.13, p=$ $\left.0.51 ; I^{2}=0 \%\right)[34,42,43]$.

\section{Physical performance}

The effects of dietary phytochemicals on the physical performance were evaluated using TUG, 30-SCST, and 6MWT (Fig. 5). TUG scores were significantly decreased in the phytochemical group compared to those who received placebo $(\mathrm{n}=6 ;-0.5 \mathrm{~s} ; 95 \% \mathrm{CI}-0.84$ to $\left.-0.15, p<0.01 ; I^{2}=18.5 \%\right)[34,35,38,40,41]$. By contrast, the 30-SCST was improved in those who supplemented with phytochemicals $(\mathrm{n}=5 ; 2.73$ times; $95 \%$ CI $0.88-4.59, p<0.01 ; I^{2}=67.4 \%$ ) [36, 38, 40, 41, 43]. Similarly, a significant improvement was found in the phytochemical group regarding $6 \mathrm{MWT}(\mathrm{n}=4 ; 29.36 \mathrm{~m}$; 95\% CI 14.58-44.13, $\left.p<0.0001 ; I^{2}=0 \%\right)[34,36,38,40]$.

Publication bias was assessed by funnel plots and Egger's regression test (Fig. 6). Visual inspection of all funnel plots did not reveal significant asymmetry. Likewise, Egger's linear regression tests did not identify any evidence of obvious reporting bias among the comparisons.

\section{Subgroup analysis}

Subgroup analysis was performed according to mean age, duration of the intervention, and origin of the population studied (Table 4). Regarding the mean age 


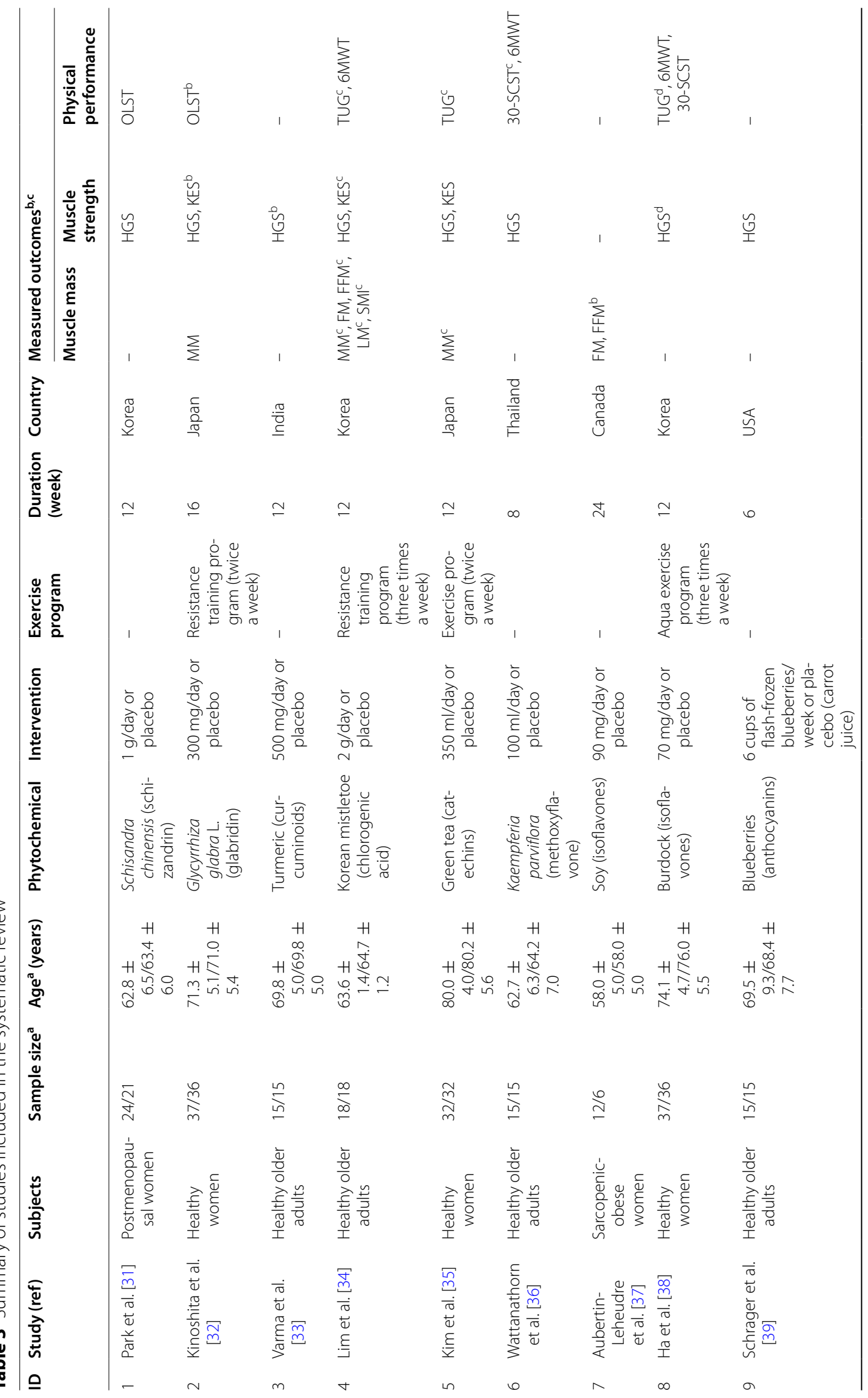




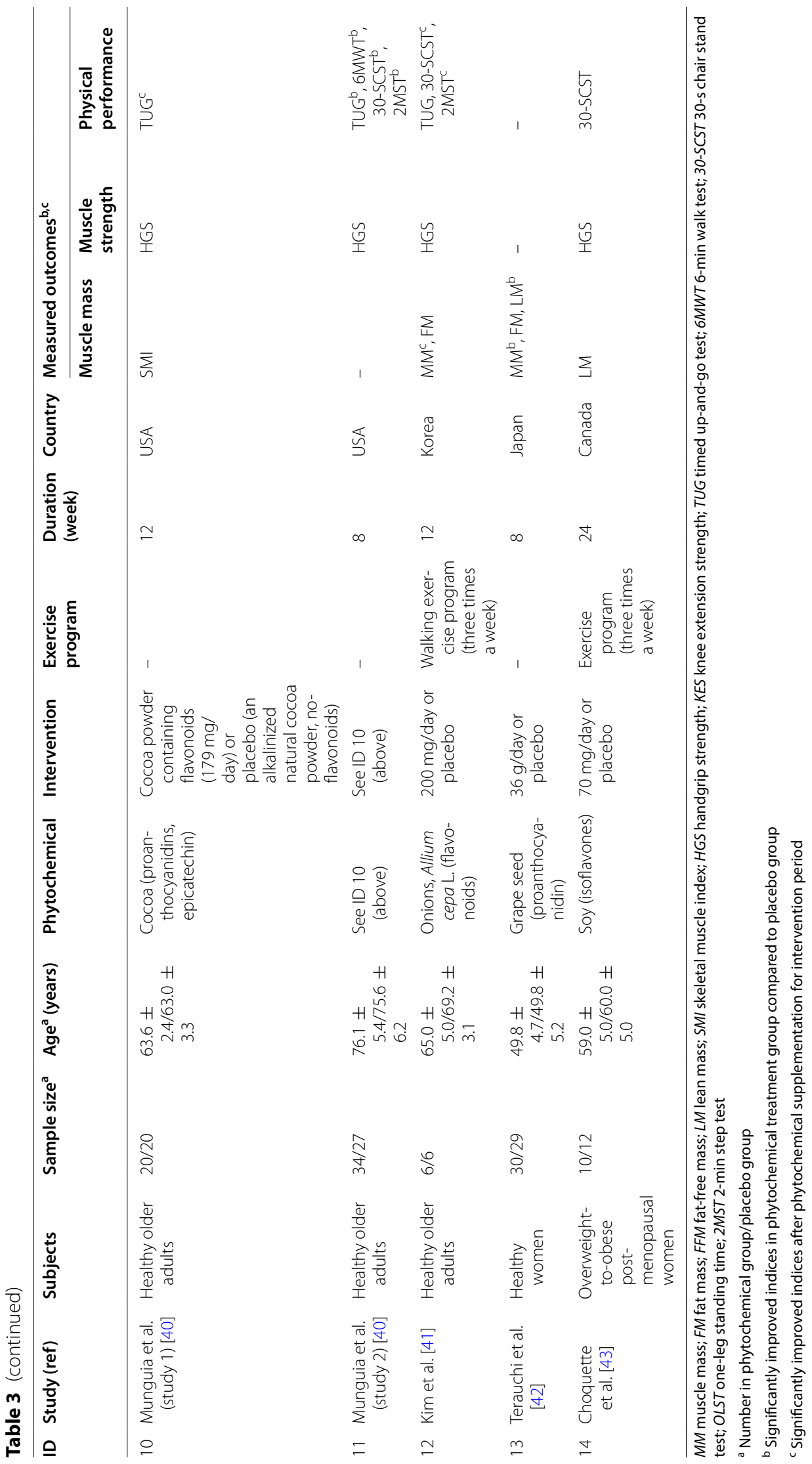




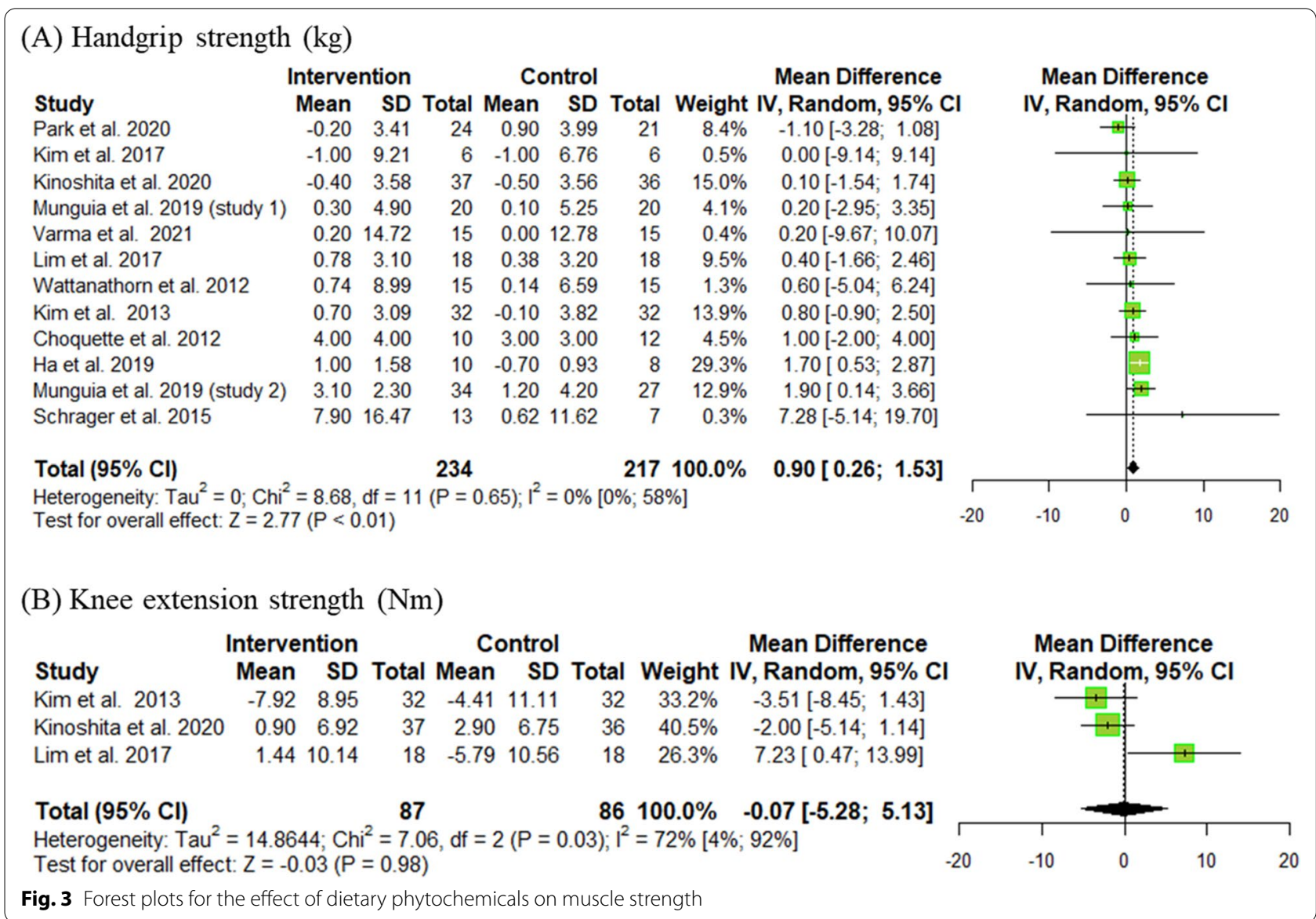

of the subjects, subgroups were assessed based on 'older adult' criteria, typically defined as 65 years old or older $[44,45]$. HGS did not change in subjects aged $\geq$ 65 years $(\mathrm{n}=6 ; 1.24 \mathrm{~kg} ; 95 \%$ CI $0.49-1.99, p<0.001$; $\left.I^{2}=0 \%\right)$, while the original effect changed in subjects aged $<65$ years $(\mathrm{n}=6 ; 0.02 \mathrm{~kg} ; 95 \% \mathrm{CI}-1.17$ to 1.21 , $\left.p<0.97 ; I^{2}=0 \%\right)$. These results were consistent in TUG, 30-SCST, and 6MWT.

Regarding the intervention duration, three subgroups were assessed based on the median value of the intervention period; (i) $<12$ weeks, (ii) 12 weeks, and (iii) $>12$ weeks. HGS and $30-$ SCST results remained unchanged in subjects who supplemented with phytochemicals for 12 weeks (HGS: $\mathrm{n}=8 ; 1.02 \mathrm{~kg} ; 95 \% \mathrm{CI}$ $0.31-1.74, p=0.01 ; I^{2}=0 \% ; 30-S C S T: \mathrm{n}=3 ; 2.97$ times; 95\% CI $\left.0.66-5.29, p=0.01 ; I^{2}=0 \%\right)$. Similarly, no difference was found in those who supplemented with phytochemicals for < 12 weeks (HGS: $\mathrm{n}$ $=2 ; 1.74 \mathrm{~kg} ; 95 \% \mathrm{CI}-3.39$ to $6.88, p=0.51 ; I^{2}=0 \%$; 30-SCST: $\mathrm{n}=1 ; 2.26$ times; $95 \% \mathrm{CI}-3.58$ to $8.10, p$ $=0.45$ ) or > 12 weeks (HGS: $\mathrm{n}=2 ; 0.30 \mathrm{~kg} ; 95 \% \mathrm{CI}$ -1.13 to $1.74, p=0.68 ; I^{2}=0 \%$; 30-SCST: $\mathrm{n}=1$; 1.00 times; $95 \% \mathrm{CI}-4.04$ to $6.04, p=0.70)$. There was insufficient data to perform subgroup analysis for TUG and 6MWT.

Concerning the study population, nine studies were conducted in Asia [31-36, 38, 41, 42] and four in the USA [39, 40] or Canada [37, 43]. HGS, 30-SCST, and $6 \mathrm{MWT}$ evaluations were not changed in both populations. However, while the TUG results had not changed in the USA or Canada, the original effect had changd in the Asian countries. There were insufficient data to perform further subgroup analyzes based on gender or dose of phytochemicals.

\section{Discussion}

This systematic review and meta-analysis analyzed the current trends in clinical research of dietary phytochemicals for the treatment of sarcopenia and, secondly, evaluated the benefits of phytochemical supplementation on muscle health in older adults ( $\geq 40$ years). The findings demonstrated that dietary phytochemicals exerted overall significant effects on MS (HGS) and physical performance (TUG, 30-SCST, and 6MWT) when pooling the results of included studies. Although the MM (MM, FM, and LM) results did not confirm any significant 


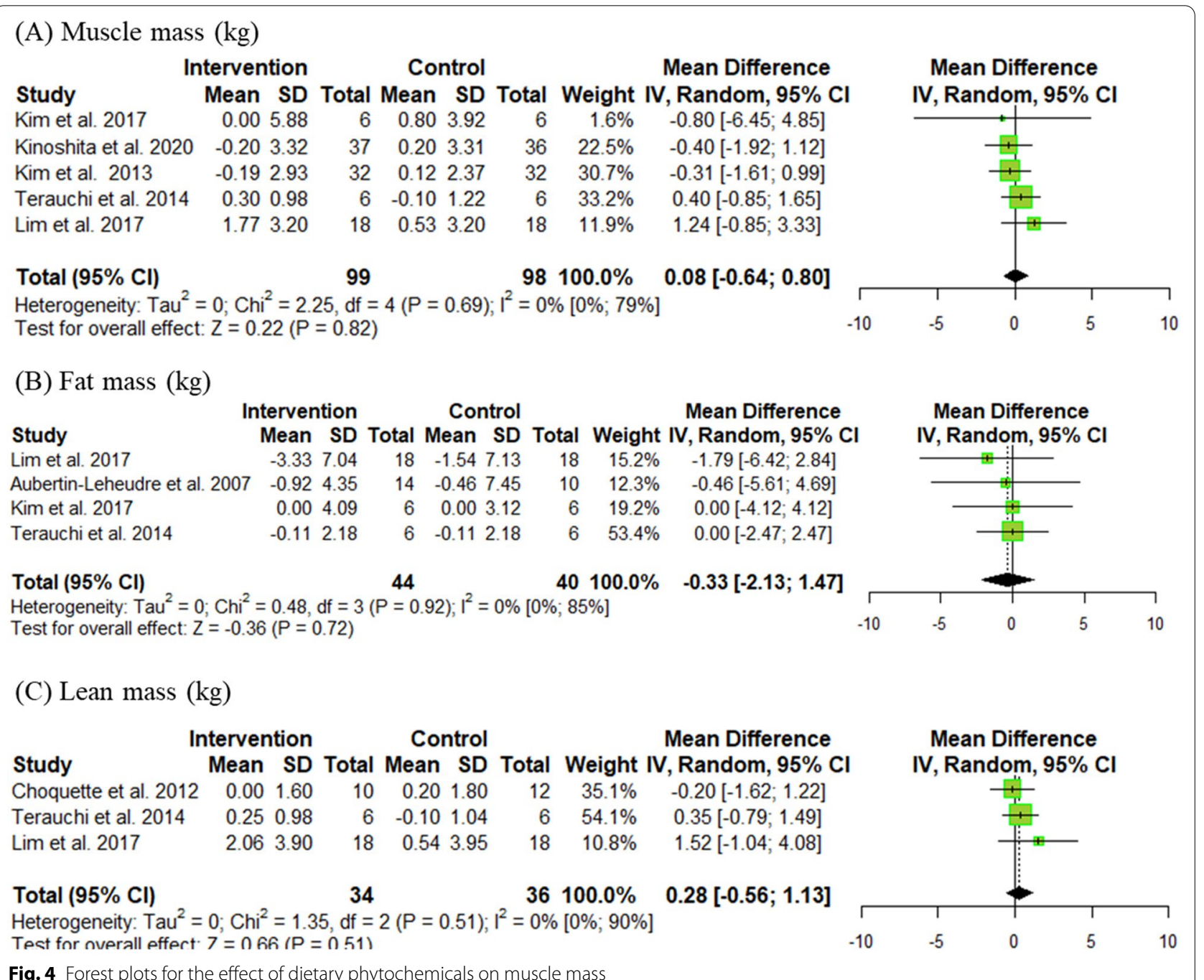

improvement, the overall results supported the benefits of phytochemicals on muscle health in healthy older adults.

We included 14 prospective studies in our meta-analysis and extracted data according to their characteristics. Across these studies, we identified three different types of outcomes related to muscle health, MM, MS, and physical performance. The most studied indicator of muscle health in older adults was HGS. Among the 12 studies that measured HGS data, 11 suggested that supplementation with phytochemicals increased HGS in older adults compared to placebo groups. Due to a sufficient number of studies focusing on this outcome, a meta-analysis was performed. It indicated that the phytochemicals group improved HGS by $0.9 \mathrm{~kg}$ compared to the placebo group after the intervention period. However, this result varies with the age of the subjects, indicating that age seems to impact the results. Notably, HGS increased significantly in the phytochemical group among subjects aged $\geq$ 65 years. Previous studies showed a strong association between HGS and nutritional supplements, particularly protein, vitamin $\mathrm{D}$, and amino acids, in older adults aged $\geq 65$ years [46-50]. However, the results did not vary with the origin of the population (Asia vs. America or Canada) or intervention periods.

Fourteen studies were of high quality, and all major domains had a low risk of bias. The high risk of bias in certain trials was due to the inappropriate statistical analysis without considering baseline characteristics and covariates [41] and the probability that placebo ingredients will affect the outcome [39]. In addition, although all studies stated that allocation was randomly generated and concealed, detailed descriptions of the methods used were not clearly mentioned, which raised uncertainty about the outcomes and made judgments about the risk of bias unclear. Therefore, the accuracy 


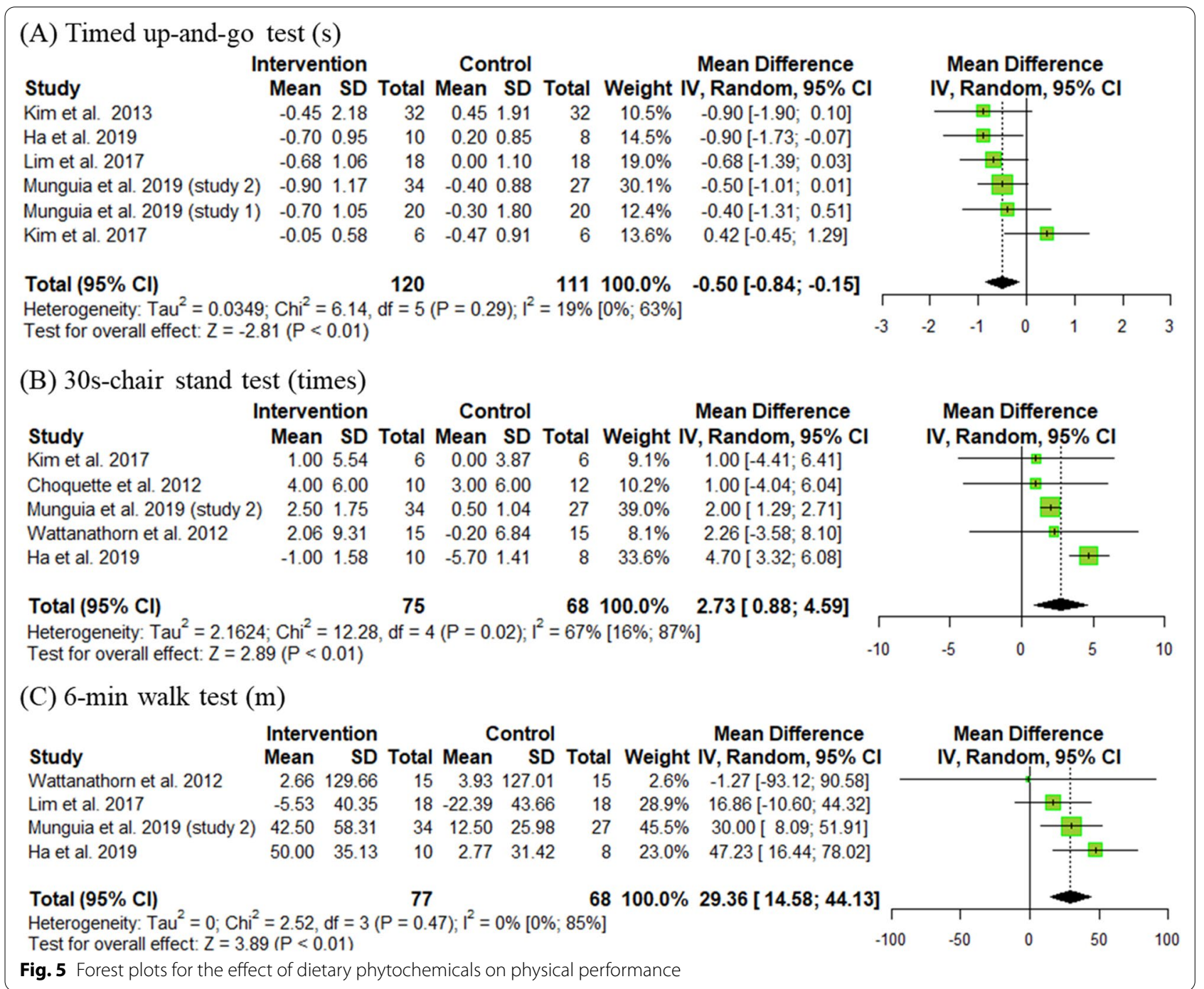

of these findings might be limited, and interpretation should be made with caution.

To the best of our knowledge, this is the first systematic review and meta-analysis to evaluate the effect of dietary phytochemicals on age-related muscle health using RCTs. Botanical foods have been widely used in traditional medical remedies to treat diseases and provide various health benefits. A wide array of phytochemicals has been identified in medicinal plants, such as flavonoids, phenolic acids, carotenoids, and anthocyanins, which have diverse biological activities, including anti-inflammatory, antioxidant, anticancer, immune, and neuroprotective effects [51]. To date, although studies of the effectiveness of dietary phytochemicals on muscle health in animals and in vitro are numerous and promising, studies in humans are still very few. Thus, the current review is meaningful in that it emphasizes the need for human intervention studies to demonstrate the effects of phytochemicals on muscle health.

Some limitations were identified in this systematic review. First, the various interventions included in the review led to heterogeneity between studies, which may be because of clinical diversity or methodological diversity (e.g., variabilities in the study design, diversified biases). Thus, we performed the meta-analysis with a random effect model to incorporate heterogeneity. Second, inadequate statistical power for subgroup analyses 

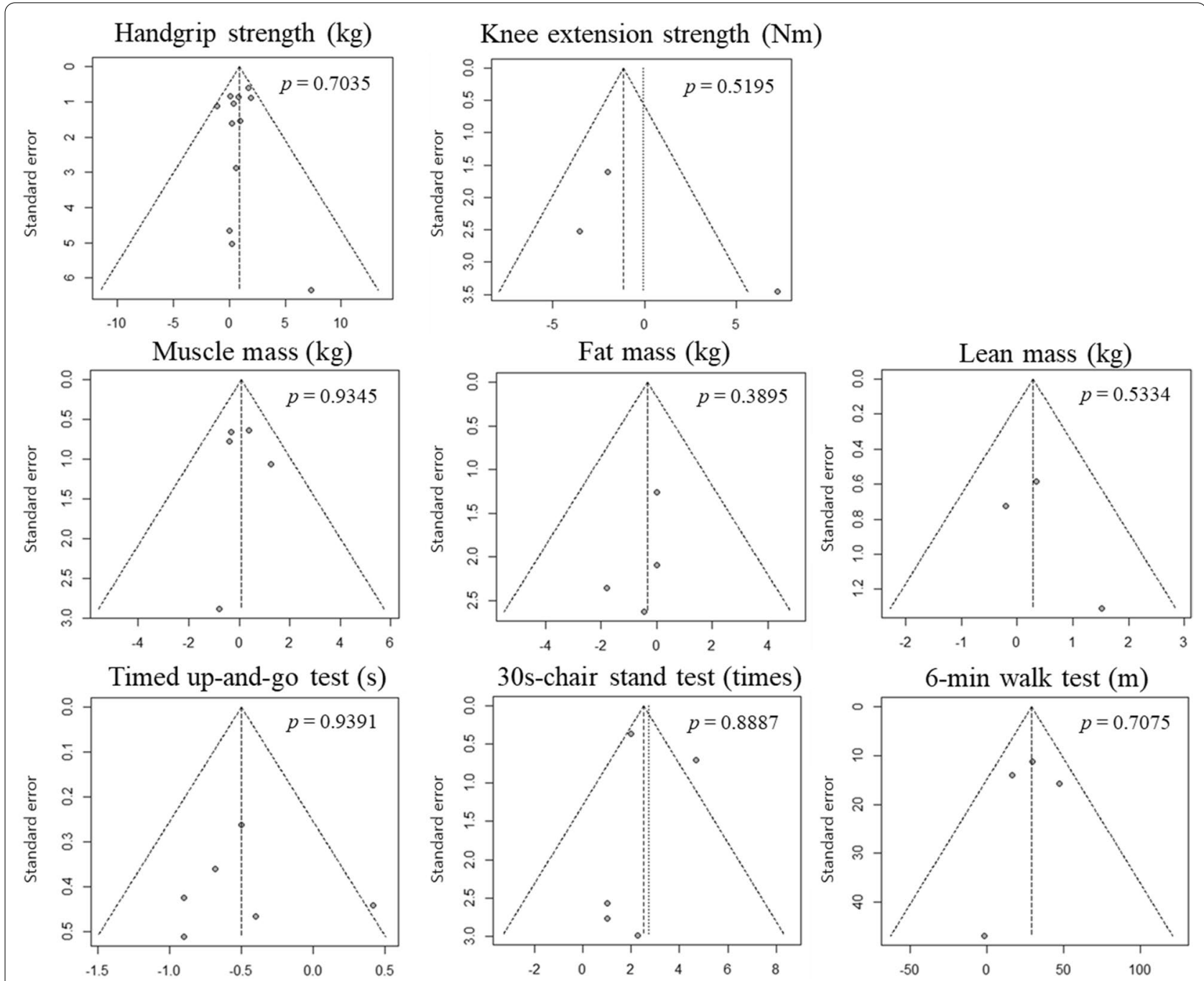

Fig. 6 Funnel plots of studies examining the effects of dietary phytochemicals on muscle health in older adults

was noted. Several subgroups (such as intervention durations for HGS) included a small number of RCTs (less than three), which may not have adequate power for detecting differences among subgroups. Thus, the results of such subgroup analyses should be cautiously interpreted. Third, the results included in this review did not include biomarkers, such as gene expression related to protein synthesis and degradation. Although this may have provided further insights given the suggested mechanisms of action of botanical treatments, there were insufficient RCTs that included biomarkers as the primary outcome of human subjects to perform systematic reviews. Nevertheless, the findings could still provide insights into the effects of phytochemicals in plant-based foods on muscle health in older adults as a non-pharmaceutical strategy. 
Table 4 Subgroup analyses of mean changes in muscle strength for HGS and physical performance for TUG, 30-SCST, and 6MWT

\begin{tabular}{|c|c|c|c|c|c|c|c|c|c|c|}
\hline & \multicolumn{5}{|c|}{ Changes in HGS (kg) } & \multicolumn{5}{|c|}{ Changes in TUG (s) } \\
\hline & $\mathrm{n}$ & Effect $(95 \% \mathrm{Cl})$ & $p^{\mathrm{a}}$ & $I^{2}(\%)$ & $p^{b}$ & $\mathrm{n}$ & Effect $(95 \% \mathrm{Cl})$ & $P^{a}$ & $I^{2}(\%)$ & $p^{2)}$ \\
\hline \multicolumn{11}{|l|}{ Mean age } \\
\hline$\geq 65$ years & 6 & $1.24(0.49,1.99)$ & 0.001 & 0 & 0.52 & 3 & $-0.66(-1.06,-0.26)$ & 0.001 & 0 & 0.63 \\
\hline$<65$ years & 6 & $0.02(-1.17,1.21)$ & 0.970 & 0 & 0.90 & 3 & $-0.25(-0.91,0.41)$ & 0.460 & 48 & 0.15 \\
\hline \multicolumn{11}{|c|}{ Origin of the population } \\
\hline Asia & 8 & $0.74(0.02,1.45)$ & 0.040 & 0 & 0.54 & 4 & $-0.51(-1.11,0.09)$ & 0.090 & 51 & 0.11 \\
\hline America or Canada & 4 & $1.46(0.10,2.82)$ & 0.040 & 0 & 0.62 & 2 & $-0.48(-0.92,-0.03)$ & 0.040 & 0 & 0.85 \\
\hline \multicolumn{11}{|c|}{ Duration of the intervention } \\
\hline$<12$ weeks & 2 & $1.74(-3.39,6.88)$ & 0.510 & 0 & 0.34 & 0 & NA & & & \\
\hline 12 weeks & 8 & $1.02(0.31,1.74)$ & 0.005 & 0 & 0.47 & 6 & & & & \\
\hline \multirow[t]{3}{*}{$>12$ weeks } & 2 & $0.30(-1.13,1.74)$ & 0.680 & 0 & 0.61 & 0 & & & & \\
\hline & \multicolumn{5}{|c|}{ Changes in 30-SCST (times) } & \multicolumn{5}{|c|}{ Changes in 6MWT (m) } \\
\hline & $\mathrm{n}$ & Effect $(95 \% \mathrm{Cl})$ & $p^{\mathrm{a}}$ & $I^{2}(\%)$ & $p^{\mathrm{b}}$ & $n$ & Effect $(95 \% \mathrm{Cl})$ & $p^{a}$ & $I^{2}(\%)$ & $p^{\mathrm{b}}$ \\
\hline \multicolumn{11}{|l|}{ Mean age } \\
\hline$\geq 65$ years & 2 & $3.28(0.64,5.92)$ & 0.010 & 91 & 0.001 & 2 & $35.79(17.94,53.65)$ & 0.000 & 0 & 0.37 \\
\hline$<65$ years & 3 & $1.36(-1.76,4.48)$ & 0.390 & 0 & 0.94 & 2 & $15.37(-10.94,41.69)$ & 0.250 & 0 & 0.71 \\
\hline \multicolumn{11}{|c|}{ Origin of the population } \\
\hline Asia & 3 & $4.13(2.39,5.87)$ & 0.000 & 9 & 0.33 & 3 & $28.76(4.83,52.70)$ & 0.020 & 20 & 0.28 \\
\hline America or Canada & 2 & $1.98(1.28,2.68)$ & 0.000 & 0 & 0.70 & 1 & $30.00(8.09,51.91)$ & 0.007 & - & - \\
\hline \multicolumn{11}{|c|}{ Duration of the intervention } \\
\hline$<12$ weeks & 1 & $2.26(-3.58,8.10)$ & 0.450 & - & - & 0 & NA & & & \\
\hline 12 weeks & 3 & $2.97(0.66,5.29)$ & 0.010 & 83 & 0.001 & 3 & & & & \\
\hline$>12$ weeks & 1 & $1.00(-4.04,6.04)$ & 0.700 & - & - & 1 & & & & \\
\hline
\end{tabular}

\section{NA not available}

${ }^{a} p$-value from the overall effect size test

${ }^{\mathrm{b}} p$-value from the heterogeneity test

\section{Acknowledgements}

Not applicable.

\section{Authors' contributions}

Conceptualization: OK; methodology, HYJ and OK; investigation, $\mathrm{HYJ}$ and OK; writing — original draft preparation, HYJ; writing — review and editing, OK; supervision, OK; project administration, OK. Both the authors read and approved the final manuscript.

\section{Funding}

This research was supported by the Bio-Synergy Research Project, Grant Number NRF-2012M3A9C4048761 Funded by the Government of South Korea (Ministry of Science, ICT, and Future Planning). The Funder had no role in the design of the study and collection, analysis, and interpretation of data and in writing the manuscript.

\section{Availability of data and materials}

All data generated or analyzed during this study are included in this published article [and its Additional information files].

\section{Declarations}

\section{Competing interests}

The authors declare that they have no competing interests.

\section{Author details}

${ }^{1}$ Department of Nutritional Science and Food Management, Ewha Womans University, Seoul 03760, Republic of Korea. ${ }^{2}$ System Health and Engineering Major in Graduate School, Ewha Womans University, Seoul 03760, Republic of Korea.

Received: 20 July 2021 Accepted: 11 August 2021

Published online: 19 August 2021

\section{References}

1. Suetta C, Magnusson S, Beyer N, Kjaer M (2007) Effect of strength training on muscle function in elderly hospitalized patients. Scand J Med Sci Sports 17:464-472

2. Dupont-Versteegden EE (2005) Apoptosis in muscle atrophy: relevance to sarcopenia. Exp Gerontol 40:473-481

3. Baumgartner RN, Koehler KM, Gallagher D, Romero L, Heymsfield SB, Ross RR, Garry PJ, Lindeman RD (1998) Epidemiology of sarcopenia among the elderly in New Mexico. Am J Epidemiol 147:755-763

4. Iannuzzi-Sucich M, Prestwood KM, Kenny AM (2002) Prevalence of sarcopenia and predictors of skeletal muscle mass in healthy, older men and women. J Gerontol A Biol Sci Med Sci 57:M772-M777

5. Janssen I, Heymsfield SB, Ross R (2002) Low relative skeletal muscle mass (sarcopenia) in older persons is associated with functional impairment and physical disability. J Am Geriatr Soc 50:889-896 
6. Cruz-Jentoft AJ, Bahat G, Bauer J, Boirie Y, Bruyère O, Cederholm T, Cooper C, Landi F, Rolland Y, Sayer AA (2019) Sarcopenia: revised European consensus on definition and diagnosis. Age Ageing 48:16-31

7. Cruz-Jentoft AJ, Sayer AA (2019) Sarcopenia. The Lancet 393:2636-2646

8. Cruz-Jentoft AJ, Landi F, Schneider SM, Zúñiga C, Arai H, Boirie Y, Chen L-K, Fielding RA, Martin FC, Michel J-P (2014) Prevalence of and interventions for sarcopenia in ageing adults: a systematic review. Report of the International Sarcopenia Initiative (EWGSOP and IWGS). Age Ageing 43:748-759

9. Manrique-Espinoza B, Salinas-Rodríguez A, Rosas-Carrasco O, GutiérrezRobledo LM, Avila-Funes JA (2017) Sarcopenia is associated with physical and mental components of health-related quality of life in older adults. J Am Med Dir Assoc 18:631. E631-636. E635

10. Tang T, Wu L, Yang L, Jiang J, Hao Q, Dong B, Yang M (2018) A sarcopenia screening test predicts mortality in hospitalized older adults. Sci Rep $8: 1-9$

11. Rygiel KA, Picard M, Turnbull DM (2016) The ageing neuromuscular system and sarcopenia: a mitochondrial perspective. J Physiol 594:4499-4512

12. Sun F, Norman IJ, While AE (2013) Physical activity in older people: a systematic review. BMC Public Health 13:1-17

13. Cummings SR, Kiel DP, Black DM (2016) Vitamin D supplementation and increased risk of falling: a cautionary tale of vitamin supplements retold. JAMA Intern Med 176:171-172

14. El Hajj C, Fares S, Chardigny JM, Boirie Y, Walrand S (2019) Vitamin D supplementation and muscle strength in pre-sarcopenic elderly Lebanese people: a randomized controlled trial. Arch Osteoporos 14:1-11

15. Gkekas NK, Anagnostis P, Paraschou V, Stamiris D, Dellis S, Kenanidis E, Potoupnis M, Tsiridis E, Goulis DG (2021) The effect of vitamin D plus protein supplementation on sarcopenia: a systematic review and metaanalysis of randomized controlled trials. Maturitas. https://doi.org/10. 1016/j.maturitas.2021.01.002

16. Remelli F, Vitali A, Zurlo A, Volpato S (2019) Vitamin D deficiency and sarcopenia in older persons. Nutrients 11:2861

17. Rondanelli M, Klersy C, Terracol G, Talluri J, Maugeri R, Guido D, Faliva MA, Solerte BS, Fioravanti M, Lukaski H (2016) Whey protein, amino acids, and vitamin $D$ supplementation with physical activity increases fat-free mass and strength, functionality, and quality of life and decreases inflammation in sarcopenic elderly. Am J Clin Nutr 103:830-840

18. Uchitomi R, Oyabu M, Kamei Y (2020) Vitamin d and sarcopenia: potential of vitamin D supplementation in sarcopenia prevention and treatment. Nutrients 12:3189

19. Ten Haaf DS, Nuijten MA, Maessen MF, Horstman AM, Eijsvogels TM, Hopman MT (2018) Effects of protein supplementation on lean body mass, muscle strength, and physical performance in nonfrail communitydwelling older adults: a systematic review and meta-analysis. Am J Clin Nutr 108:1043-1059

20. Tieland $M$, Dirks $M L$, van der Zwaluw $N$, Verdijk LB, Van De Rest $\mathrm{O}$, de Groot LC, Van Loon LJ (2012) Protein supplementation increases muscle mass gain during prolonged resistance-type exercise training in frail elderly people: a randomized, double-blind, placebo-controlled trial. J Am Med Dir Assoc 13:713-719

21. Witard OC, Combet E, Gray SR (2020) Long-chain n-3 fatty acids as an essential link between musculoskeletal and cardio-metabolic health in older adults. Proc Nutr Soc 79:47-55

22. Liao C-D, Chen H-C, Huang S-W, Liou T-H (2019) The role of muscle mass gain following protein supplementation plus exercise therapy in older adults with sarcopenia and frailty risks: a systematic review and metaregression analysis of randomized trials. Nutrients 11:1713

23. Joseph SV, Edirisinghe I, Burton-Freeman BM (2016) Fruit polyphenols: a review of anti-inflammatory effects in humans. Crit Rev Food Sci Nutr 56:419-444

24. Yaqub S, Farooq U, Shafi A, Akram K, Murtaza MA, Kausar T, Siddique F (2016) Chemistry and functionality of bioactive compounds present in persimmon. J Chem. https://doi.org/10.1155/2016/3424025

25. McInnes MD, Moher D, Thombs BD, McGrath TA, Bossuyt PM, Clifford T, Cohen JF, Deeks JJ, Gatsonis C, Hooft L (2018) Preferred reporting items for a systematic review and meta-analysis of diagnostic test accuracy studies: the PRISMA-DTA statement. Jama 319:388-396

26. Sterne JA, Savović J, Page MJ, Elbers RG, Blencowe NS, Boutron I, Cates CJ, Cheng H-Y, Corbett MS, Eldridge SM (2019) RoB 2: a revised tool for assessing risk of bias in randomised trials. BMJ. https://doi.org/10.1136/ bmj.14898

27. Egger M, Smith GD, Phillips AN (1997) Meta-analysis: principles and procedures. BMJ 315:1533-1537

28. Higgins JP, Thomas J, Chandler J, Cumpston M, Li T, Page MJ, Welch VA (2019) Cochrane handbook for systematic reviews of interventions. Wiley, Hoboken

29. Sterne JA, Egger M (2005) Regression methods to detect publication and other bias in meta-analysis. Publication bias in meta-analysis: prevention, assessment and adjustments. Wiley, Hoboken, pp 99-110

30. Schwarzer $G$ (2007) meta: an R package for meta-analysis. R news 7:40-45

31. Park J, Han S, Park H (2020) Effect of Schisandra chinensis extract supplementation on quadriceps muscle strength and fatigue in adult women: a randomized, double-blind, placebo-controlled trial. Int J Environ Res Public Health 17:2475

32. Kinoshita T, Maruyama K, Yamamoto N, Saito I (2020) The effects of dietary licorice flavonoid oil supplementation on body balance control in healthy middle-aged and older Japanese women undergoing a physical exercise intervention: a randomized, double-blind, placebo-controlled trial. Aging Clin Exp Res. https://doi.org/10.1007/s40520-020-01513-3

33. Varma K, Amalraj A, Divya C, Gopi S (2021) The efficacy of the novel bioavailable curcumin (cureit) in the management of sarcopenia in healthy elderly subjects: a randomized, placebo-controlled, double-blind clinical study. J Med Food 24:40-49

34. Lim NJ, Shin JH, Kim HJ, Lim Y, Kim JY, Lee WJ, Han SJ, Kwon O (2017) A combination of Korean mistletoe extract and resistance exercise retarded the decline in muscle mass and strength in the elderly: a randomized controlled trial. Exp Gerontol 87:48-56

35. Kim H, Suzuki T, Saito K, Yoshida H, Kojima N, Kim M, Sudo M, Yamashiro Y, Tokimitsu I (2013) Effects of exercise and tea catechins on muscle mass, strength and walking ability in community-dwelling elderly Japanese sarcopenic women: a randomized controlled trial. Geriatr Gerontol Int 13:458-465

36. Wattanathorn J, Muchimapura S, Tong-Un T, Saenghong N, ThukhumMee W, Sripanidkulchai B (2012) Positive modulation effect of 8-week consumption of Kaempferia parviflora on health-related physical fitness and oxidative status in healthy elderly volunteers. Evid Based Complement Altern Med. https://doi.org/10.1155/2012/732816

37. Aubertin-Leheudre M, Lord C, Khalil A, Dionne I (2007) Six months of isoflavone supplement increases fat-free mass in obese-sarcopenic postmenopausal women: a randomized double-blind controlled trial. Eur J Clin Nutr 61:1442-1444

38. Ha M-S, Kim J-H, Ha S-M, Kim Y-S, Kim D-Y (2019) Positive influence of aqua exercise and burdock extract intake on fitness factors and vascular regulation substances in elderly. J Clin Biochem Nutr 64:73-78

39. Schrager MA, Hilton J, Gould R, Kelly VE (2015) Effects of blueberry supplementation on measures of functional mobility in older adults. Appl Physiol Nutr Metab 40:543-549

40. Munguia L, Rubio-Gayosso I, Ramirez-Sanchez I, Ortiz A, Hidalgo I, Gonzalez C, Meaney E, Villarreal F, Najera N, Ceballos G (2019) High flavonoid cocoa supplement ameliorates plasma oxidative stress and inflammation levels while improving mobility and quality of life in older subjects: a double-blind randomized clinical trial. J Gerontol Ser A 74:1620-1627

41. 철우김, 이섭곽, 지석김 (2017) 12 주간의 규칙적인 중강도 걷기 운동 과 자색양파 추출울 섭취가 노인의 신체구성 및 건강체력에 미치는 영향. 한 국 스포츠학회지 15:397-405

42. Terauchi M, Horiguchi N, Kajiyama A, Akiyoshi M, Owa Y, Kato K, Kubota T (2014) Effects of grape seed proanthocyanidin extract on menopausal symptoms, body composition, and cardiovascular parameters in middleaged women: a randomized, double-blind, placebo-controlled pilot study. Menopause 21:990-996 
43. Choquette S, Dion T, Brochu M, Dionne I (2012) Soy isoflavones and exercise to improve physical capacity in postmenopausal women. Climacteric 16:70-77

44. Orimo H, Ito H, Suzuki T, Araki A, Hosoi T, Sawabe M (2006) Reviewing the definition of "elderly." Geriatr Gerontol Int 6:149-158

45. World Health Organization. Definition of an older or elderly person. 2013. www.who.int/healthinfo/survey/ageingdefnolder/en/. Accessed 30 June 2015. 2018

46. Park S, Chae M, Park H, Park K (2021) Higher branched-chain amino acid intake is associated with handgrip strength among Korean older adults. Nutrients 13:1522

47. Tak YJ, Lee JG, Yi YH, Kim YJ, Lee S, Cho BM, Cho YH (2018) Association of handgrip strength with dietary intake in the Korean population: findings based on the seventh Korea National Health and Nutrition Examination Survey (KNHANES VII-1), 2016. Nutrients 10:1180

48. Wu T-Y (2020) Handgrip strength might possibly be improved by oral vitamin d3 supplementation in older people with sarcopenia: a systematic review and meta-analysis. Aging Med Healthc. https://doi.org/ 10.3879/AMH.114.2020.05014

49. Jang W, Ryu HK (2020) Association of low hand grip strength with protein intake in Korean female elderly: based on the Seventh Korea National Health and Nutrition Examination Survey (KNHANES VII), 2016-2018. Korean J Community Nutr 25:226-235

50. Kim B-J, Kwak MK, Lee SH, Koh J-M (2019) Lack of association between vitamin $d$ and hand grip strength in Asians: a nationwide populationbased study. Calcif Tissue Int 104:152-159

51. Liu RH (2003) Health benefits of fruit and vegetables are from additive and synergistic combinations of phytochemicals. Am J Clin Nutr 78:517S-520S

\section{Publisher's Note}

Springer Nature remains neutral with regard to jurisdictional claims in published maps and institutional affiliations.

\section{Submit your manuscript to a SpringerOpen ${ }^{\circ}$ journal and benefit from:}

- Convenient online submission

- Rigorous peer review

- Open access: articles freely available online

- High visibility within the field

- Retaining the copyright to your article

Submit your next manuscript at $\boldsymbol{\nabla}$ springeropen.com 